\title{
Atomic Distribution in Catalytic Amorphous Metals
}

\author{
Sanghita Mridha, ${ }^{1}$ David L. Jaeger, ${ }^{1,2}$ Harpreet Singh Arora, ${ }^{1,3}$ \\ Rajarshi Banerjee, ${ }^{1,2}$ and Sundeep Mukherjee ${ }^{1}$ \\ ${ }^{1}$ Department of Materials Science and Engineering, University of North Texas, Denton, TX 76203, USA \\ ${ }^{2}$ Center for Advanced Research and Technology, Department of Materials Science and Engineering, \\ University of North Texas, Denton, TX 76203, USA \\ ${ }^{3}$ Department of Mechanical Engineering, School of Engineering, Shiv Nadar University, Dadri, Gautam Buddha Nagar, \\ Uttar Pradesh 201314, India \\ Correspondence should be addressed to Sundeep Mukherjee; sundeep.mukherjee@unt.edu
}

Received 20 August 2015; Accepted 24 November 2015

Academic Editor: Domenico Acierno

Copyright (C) 2015 Sanghita Mridha et al. This is an open access article distributed under the Creative Commons Attribution License, which permits unrestricted use, distribution, and reproduction in any medium, provided the original work is properly cited.

The atomic distribution in catalytically active metallic glass alloys, $\mathrm{Pd}_{43} \mathrm{Cu}_{27} \mathrm{Ni}_{10} \mathrm{P}_{20}$ and $\mathrm{Pt}_{57.5} \mathrm{Cu}_{14.7} \mathrm{Ni}_{5.3} \mathrm{P}_{22.5}$, was investigated using three-dimensional atom probe microscopy. Atom probe analysis showed uniform distribution of constituent elements for both the starting amorphous alloys, with no phase separation. Both the crystallized alloys showed eutectic microstructure with a very sharp interface ( $\sim 0.5 \mathrm{~nm}$ as determined from atom probe). The atomic distribution in the devitrified state is explained based on the "fragile liquid" behavior for these noble-metal glassy alloys.

\section{Introduction}

Noble-metal based glassy alloys have attracted a lot of interest in recent years due to their high electrocatalytic activity and durability compared to conventional pure metal catalysts $[1,2]$. Excellent thermoplastic formability of these alloys allows synthesis of self-supporting nanowire architecture for energy storage/conversion applications $[1,2]$. This circumvents the need for support materials (e.g., carbon nanotubes) that dissolve/degrade under normal operating conditions of electrochemical devices. Further, the chemistry of these alloy systems has been shown to be very active for several electrocatalytic reactions [3, 4]. Mapping and controlling the atomic distribution in these novel catalysts will facilitate significant progress in terms of performance, cost, and durability of state-of-the-art electrochemical devices. Given their metastable nature, the active species in these bulk metallic glasses (BMGs) can be strategically tailored to achieve further enhancement in their catalytic properties. The type, distribution, and length-scale of crystallites formed during controlled devitrification of metallic glasses may be utilized as a toolbox to engineer transformative catalysts for energy storage and conversion.

Pure platinum and palladium in various (nano)morphologies dispersed on low/high aspect-ratio supports make up majority of electrocatalysts at the present time. Two catalytically active amorphous systems based on these late transition metals include $\mathrm{Pt}_{57.5} \mathrm{Cu}_{14.7} \mathrm{Ni}_{5.3} \mathrm{P}_{22.5}$ and $\mathrm{Pd}_{43} \mathrm{Cu}_{27} \mathrm{Ni}_{10} \mathrm{P}_{20}$. The palladium alloy, $\mathrm{Pd}_{43} \mathrm{Cu}_{27} \mathrm{Ni}_{10} \mathrm{P}_{20}$, is one of the best known bulk metallic glass (BMG) formers with a critical cooling rate of glass formation as low as $0.1 \mathrm{~K} / \mathrm{s}$ [5]. Alloy development efforts to replace Pd with Pt led to $\mathrm{Pt}_{57.5} \mathrm{Cu}_{14.7} \mathrm{Ni}_{5.3} \mathrm{P}_{22.5}$ metallic glass, with critical cooling rate of $20 \mathrm{~K} / \mathrm{s}$ [6] and high thermoplastic formability [1]. There are no studies to date on the atomic distribution in these catalytically active alloy systems in the (metastable) amorphous or (thermodynamically stable) devitrified state. Thermodynamic studies suggest a transition from nucleation-controlled to growth-controlled mechanism of crystallization for $\mathrm{Pd}_{43} \mathrm{Cu}_{27} \mathrm{Ni}_{10} \mathrm{P}_{20}$ alloy [7], while devitrification studies in platinum-based $\mathrm{BMG}$ have not been reported so far. Detailed investigation of the atomic distribution, composition fluctuations (due to possible phase 


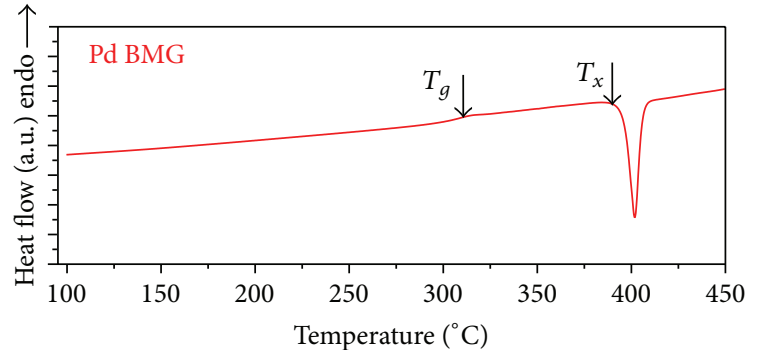

(a)

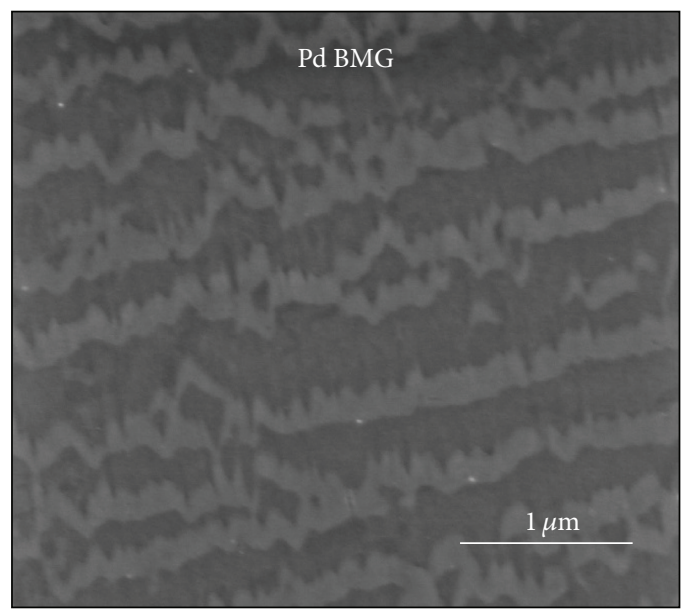

(c)

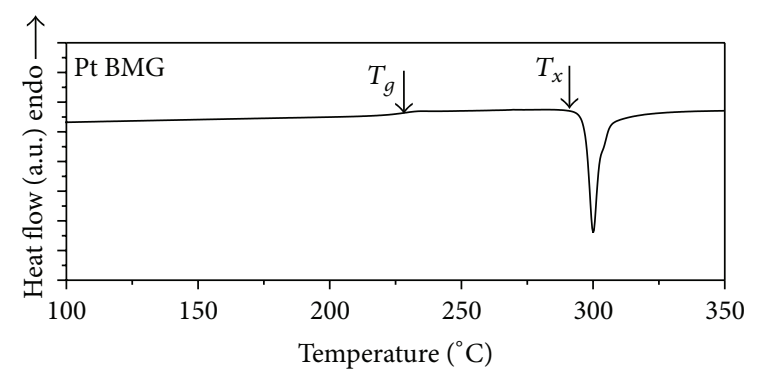

(b)

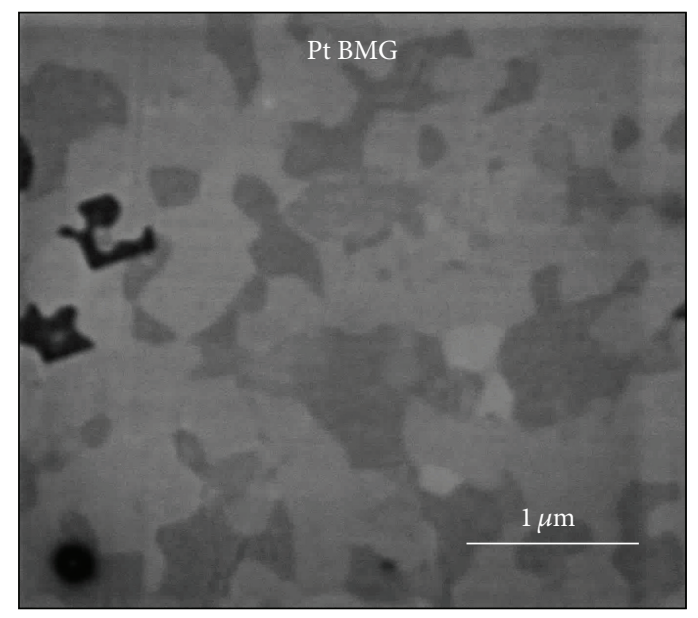

(d)

Figure 1: DSC curves for (a) $\mathrm{Pd}_{43} \mathrm{Cu}_{27} \mathrm{Ni}_{10} \mathrm{P}_{20}$ metallic glass and (b) $\mathrm{Pt}_{57.5} \mathrm{Cu}_{14.7} \mathrm{Ni}_{5.3} \mathrm{P}_{22.5}$ metallic glass; (c) SEM micrograph for the crystallized $\mathrm{Pd}_{43} \mathrm{Cu}_{27} \mathrm{Ni}_{10} \mathrm{P}_{20}$ alloy; (d) SEM micrograph for the crystallized $\mathrm{Pt}_{57.5} \mathrm{Cu}_{14.7} \mathrm{Ni}_{5.3} \mathrm{P}_{22.5}$ alloy. The glass transition and crystallization temperatures are indicated by $T_{g}$ and $T_{x}$, respectively. Pd alloy has a lamellar eutectic structure compared to an acicular eutectic structure for the Pt alloy.

separation), length-scale of the crystalline phases, and the interface between the crystallites is lacking.

In the current study, we report on the atomic distribution of the two noble-metal based BMGs, $\mathrm{Pd}_{43} \mathrm{Cu}_{27} \mathrm{Ni}_{10} \mathrm{P}_{20}$ and $\mathrm{Pt}_{57.5} \mathrm{Cu}_{14.7} \mathrm{Ni}_{5.3} \mathrm{P}_{22.5}$, investigated using three-dimensional atom-probe (3DAP) microscopy. The distribution of atoms was obtained for the as-cast amorphous (metastable) state and the corresponding (thermodynamically stable) devitrified state. Owing to its atomic-scale resolution, 3DAP technique was used to identify nanometer-scale composition fluctuations and the interface between the different phases upon devitrification of the metallic glasses. Atom probe analysis was combined with scanning electron microscopy (SEM) and $\mathrm{X}$-ray diffraction (XRD) to study the morphology, chemistry, and distribution of the crystallized phases.

\section{Experimental}

Bulk metallic glasses with nominal composition of $\mathrm{Pd}_{43} \mathrm{Cu}_{27} \mathrm{Ni}_{10} \mathrm{P}_{20}$ and $\mathrm{Pt}_{57.5} \mathrm{Cu}_{14.7} \mathrm{Ni}_{5.3} \mathrm{P}_{22.5}$ were prepared by melting high-purity constituents in vacuum-sealed glass tubes followed by water quenching from a temperature of $1000^{\circ} \mathrm{C}$ after appropriate $\mathrm{B}_{2} \mathrm{O}_{3}$ fluxing. Glass transition $\left(T_{g}\right)$ and crystallization temperature $\left(T_{x}\right)$ for both alloys were determined using differential scanning calorimetry
(DSC) at a heating rate of $20^{\circ} \mathrm{C} / \mathrm{min}$. Both the bulk metallic glass samples were crystallized by heating up to $450^{\circ} \mathrm{C}$ at a heating rate of $20^{\circ} \mathrm{C} / \mathrm{min}$ in DSC in an argon atmosphere. Microstructure analysis was done using scanning electron microscopy (FEI QUANTA 200). X-ray diffraction (XRD) analysis was done using Rigaku III Ultima X-ray diffractometer with $\mathrm{Cu}-\mathrm{K}_{\alpha}$ radiation of wavelength $1.54 \mathrm{~nm}$. 3DAP analysis was done to obtain concentration profiles and elemental distribution at different locations/interfaces of the starting amorphous and the crystallized specimens. For 3DAP studies, laser-pulsed local electrode atom probe (LEAP 3000X HR) operating at a wavelength of $532 \mathrm{~nm}$ and 12 ps pulse duration was used. Specimens for 3DAP were prepared using focused ion beam (FIB) lift-out technique (FEI Nova 200 dual beam). Atom probe tips were prepared using $30 \mathrm{kV}$ ion beam with annular milling patterns followed by final tip shaping using $5 \mathrm{kV}$ ion beam.

\section{Results and Discussion}

Differential scanning calorimetry (DSC) curves for both ascast metallic glasses are shown in Figures 1(a) and 1(b). The glass transition temperature $\left(T_{g}\right)$ and crystallization temperature $\left(T_{x}\right)$ for Pd-based metallic glass was found to be $305^{\circ} \mathrm{C}$ and $390^{\circ} \mathrm{C}$, respectively, whereas, for Pt-based metallic 


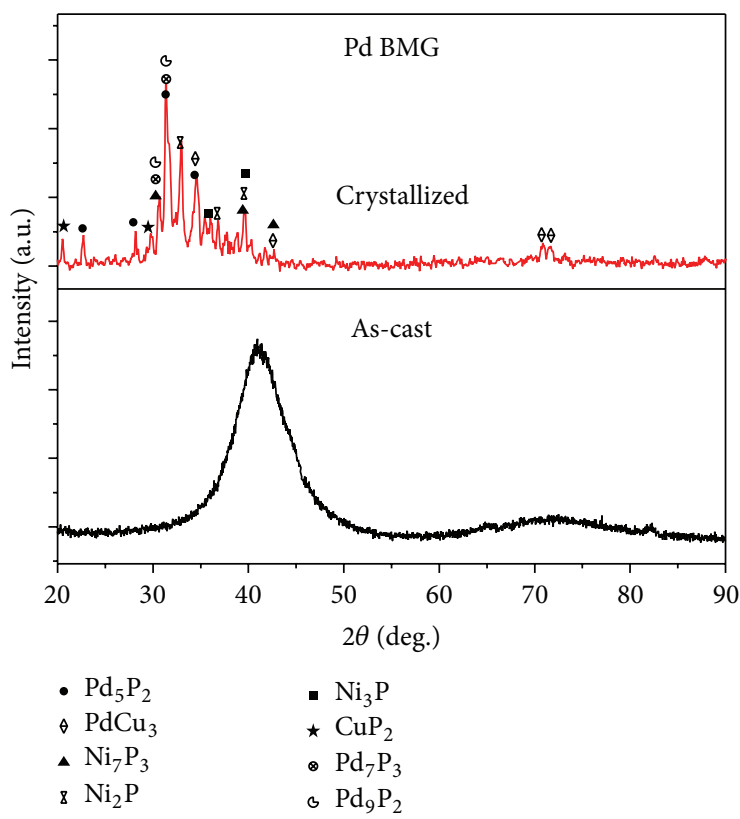

(a)

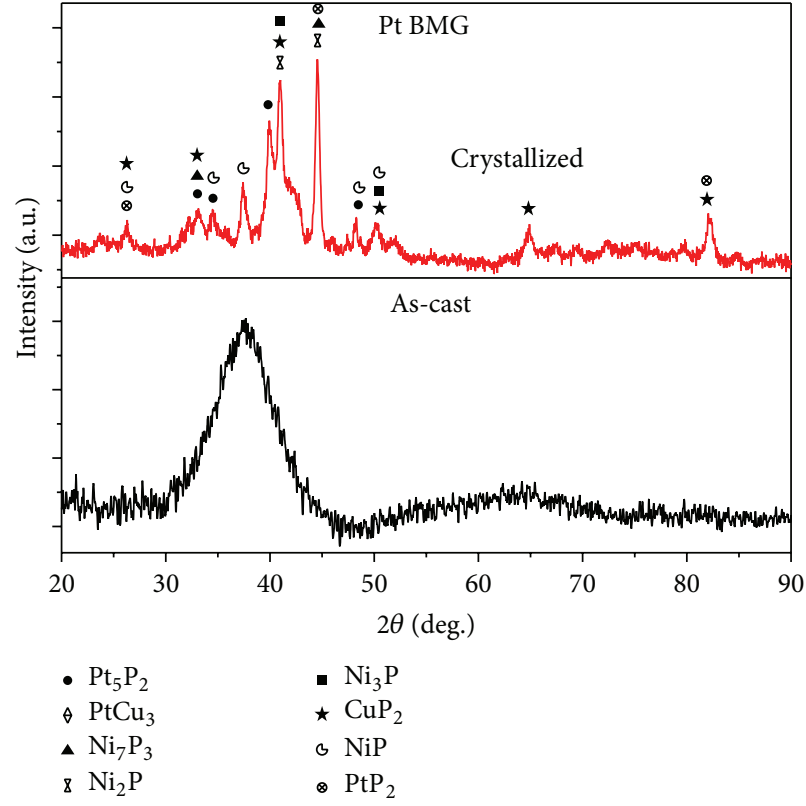

(b)

Figure 2: XRD analysis curves for (a) $\mathrm{Pd}_{43} \mathrm{Cu}_{27} \mathrm{Ni}_{10} \mathrm{P}_{20}$ metallic glass and (b) $\mathrm{Pt}_{57.5} \mathrm{Cu}_{14.7} \mathrm{Ni}_{5.3} \mathrm{P}_{22.5}$ metallic glass in as-cast amorphous and crystallized form. The different crystalline phases are marked alongside the XRD peaks.

glass, the values were $225^{\circ} \mathrm{C}$ and $290^{\circ} \mathrm{C}$, respectively. A large supercooled liquid region $\left(\Delta T=T_{x}-T_{g}\right)$ of $85^{\circ} \mathrm{C}$ and $65^{\circ} \mathrm{C}$ was found for the Pd alloy and Pt alloy, respectively. The wide supercooled liquid region allows thermoplastic forming of these alloys down to a few nanometers. SEM micrographs for the fully crystallized Pd and Pt alloys are shown in Figures $1(\mathrm{c})$ and $1(\mathrm{~d})$, respectively. The Pt alloy has an acicular eutectic structure whereas Pd alloy has a lamellar eutectic structure with submicron length-scale. The difference in the structures may be attributed to the difference in critical cooling rates for the two alloy systems. The critical cooling rate for $\mathrm{Pd}_{43} \mathrm{Cu}_{27} \mathrm{Ni}_{10} \mathrm{P}_{20}$ is two orders of magnitude lower compared to $\mathrm{Pt}_{57.5} \mathrm{Cu}_{14.7} \mathrm{Ni}_{5.3} \mathrm{P}_{22.5}$ metallic glass. Due to the higher cooling rate required for vitrifying $\mathrm{Pt}_{57.5} \mathrm{Cu}_{14.7} \mathrm{Ni}_{5.3} \mathrm{P}_{22.5}$, it is likely to be further away from its corresponding equilibrium structure compared to the Pd alloy. The acicular structure for the Pt alloy is likely due to its tendency to reduce excess free energy by dissociating into smaller features. Fragmentation of lamellar structure to smaller acicular structure has been reported previously [8]. XRD results for the as-cast and fully crystallized samples of both alloys are shown in Figures 2(a) and 2(b). The as-cast samples show a broad peak indicating fully amorphous structure. It is seen from XRD results that the crystalline products formed in both the alloys are very similar, consisting mostly of metal-metalloid binary phases.

To investigate any nanoscale composition fluctuations in the as-cast metallic glass, atom probe studies were carried out comprising 3D reconstruction and elemental distribution (Figure 3). The as-cast structure for both the alloys shows uniform distribution of different elements, without any indication of phase separation. Cyclic voltammetry on these amorphous metal compositions showed increase in electrochemical surface area (ECSA), which was attributed to dealloying of less noble constituents [1]. The random mixture of noble/less-noble atoms in the starting amorphous alloy without preferential surface segregation favors dealloying induced surface area enhancement. No evidence of short range ordering is seen, indicating compositional homogeneity down to the nanometer scale.

The atom probe results for the crystallized Pd-based metallic glass are shown in Figure 4 and summarized in Table 1. The LEAP analysis of the fully crystallized alloy showed seven distinct phases: $\mathrm{Pd}_{5} \mathrm{P}_{2}, \mathrm{Cu}_{3} \mathrm{Pd}, \mathrm{Pd}_{4} \mathrm{Ni}_{3} \mathrm{P}_{3}$, and small volume fraction of four complex quaternary phosphides. Earlier reports on crystallization in $\mathrm{Pd}-\mathrm{Cu}-\mathrm{Ni}-\mathrm{P}$ alloys also showed the formation of binary, ternary, and higher order phosphides [9-12]. The corresponding phases could not be identified in XRD because of lack of database on complex higher order phosphides. The 3DAP reconstruction as well as elemental distribution for crystallized Pt-based metallic glass was very similar to Pd alloy (Figure 5). The 3DAP results for crystallized Pt alloy are summarized in Table 2. The crystallized microstructure for Pt-based metallic glass comprises three distinct regions (i) Pt-rich $\left(\mathrm{Pt}_{3} \mathrm{PCu}\right)$, (ii) P-rich $\left(\mathrm{PtP}_{2}\right)$, and (iii) a quaternary phase of $\mathrm{Pt}-\mathrm{Cu}-\mathrm{Ni}-\mathrm{P}$.

The presence of multiple crystalline phases in each of the two metallic glasses (Tables 1 and 2) demonstrates the complexity of phase formation in these alloys. DSC shows a single sharp devitrification peak (Figure 1), characteristic of eutectic crystallization, which is seen in microstructure as well. Phase-separation induced crystallization has been reported for a number of different metallic glasses [13]. However, there is no evidence of phase separation in the starting amorphous structure of the metallic glasses investigated in 
TABLE 1: Elemental composition (at. \%) obtained using atom probe microscopy of different phases identified in crystallized $\mathrm{Pd}_{43} \mathrm{Cu}_{27} \mathrm{Ni}_{10} \mathrm{P}_{20}$ metallic glass.

\begin{tabular}{|c|c|c|c|c|}
\hline Elements (atomic \%) & Phase 1 & Phase 2 & Phase 3 & $\begin{array}{l}\text { Quaternary phosphide } \\
\text { phase }\end{array}$ \\
\hline $\mathrm{Pd}$ & 69.9 & 20.8 & 39.6 & \multirow{4}{*}{$\begin{array}{l}\mathrm{Pd}_{48.9} \mathrm{Cu}_{16.2} \mathrm{Ni}_{8.4} \mathrm{P}_{26.7} \\
+\mathrm{Pd}_{37.3} \mathrm{Cu}_{26.9} \mathrm{Ni}_{12.2} \mathrm{P}_{23.6} \\
+\mathrm{Pd}_{32.4} \mathrm{Cu}_{16.3} \mathrm{Ni}_{23.1} \mathrm{P}_{28.2} \\
+\mathrm{Pd}_{44.4} \mathrm{Cu}_{24.0} \mathrm{Ni}_{9.6} \mathrm{P}_{21.9}\end{array}$} \\
\hline $\mathrm{Cu}$ & 2.0 & 77.5 & 0.7 & \\
\hline $\mathrm{Ni}$ & 0.9 & 0.0 & 27.5 & \\
\hline $\mathrm{P}$ & 27.2 & 1.7 & 32.2 & \\
\hline Likely phase & $\mathrm{Pd}_{7} \mathrm{P}_{3}$ & $\mathrm{PdCu}_{3}$ & $\mathrm{Pd}_{4} \mathrm{Ni}_{3} \mathrm{P}_{3}$ & $\begin{array}{l}\text { Mixture of quaternary } \\
\text { Pd-rich phosphides }\end{array}$ \\
\hline
\end{tabular}

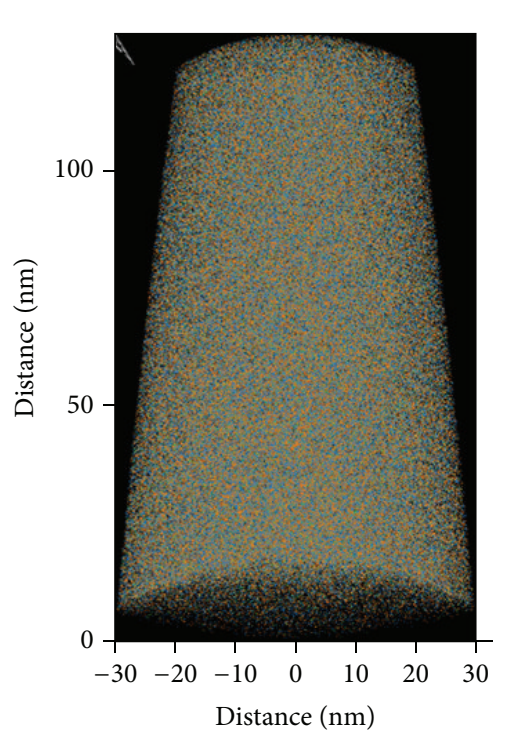

(a)

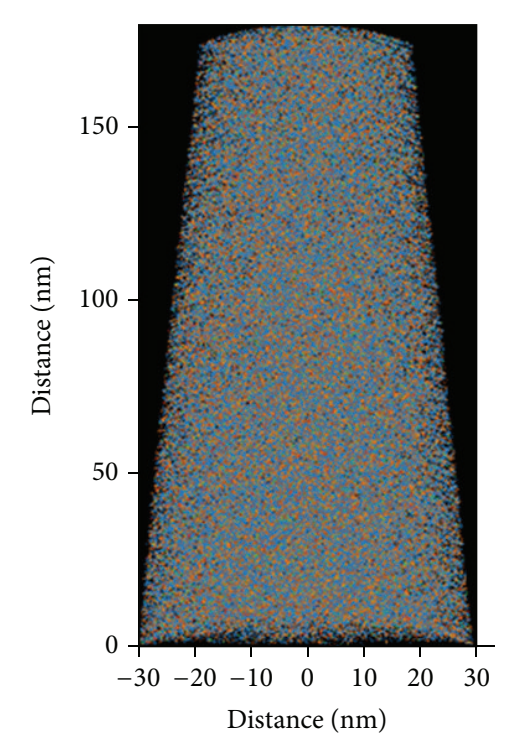

(c)

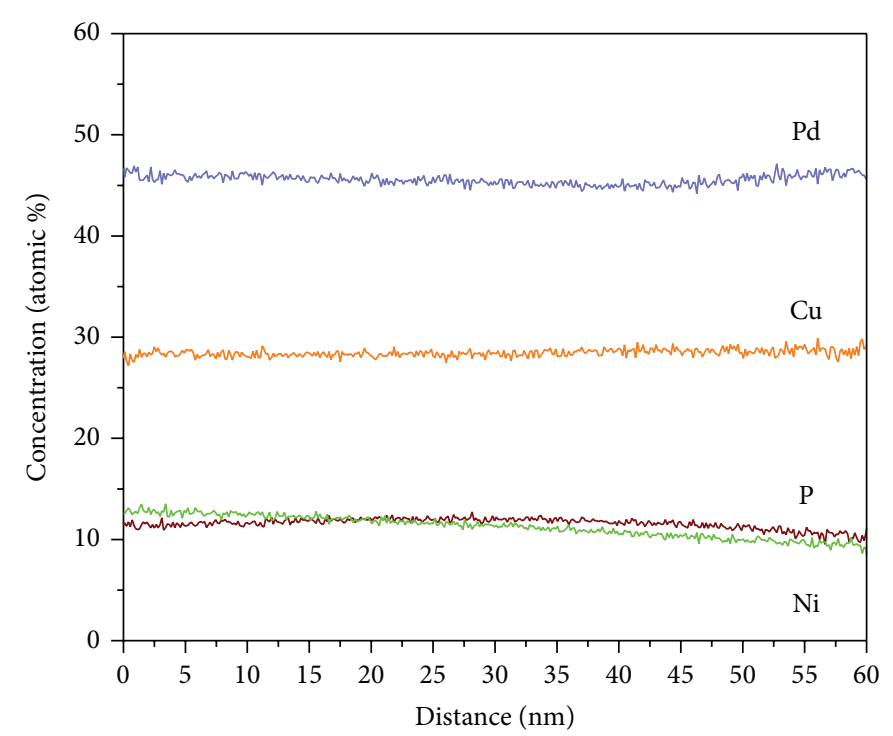

(b)

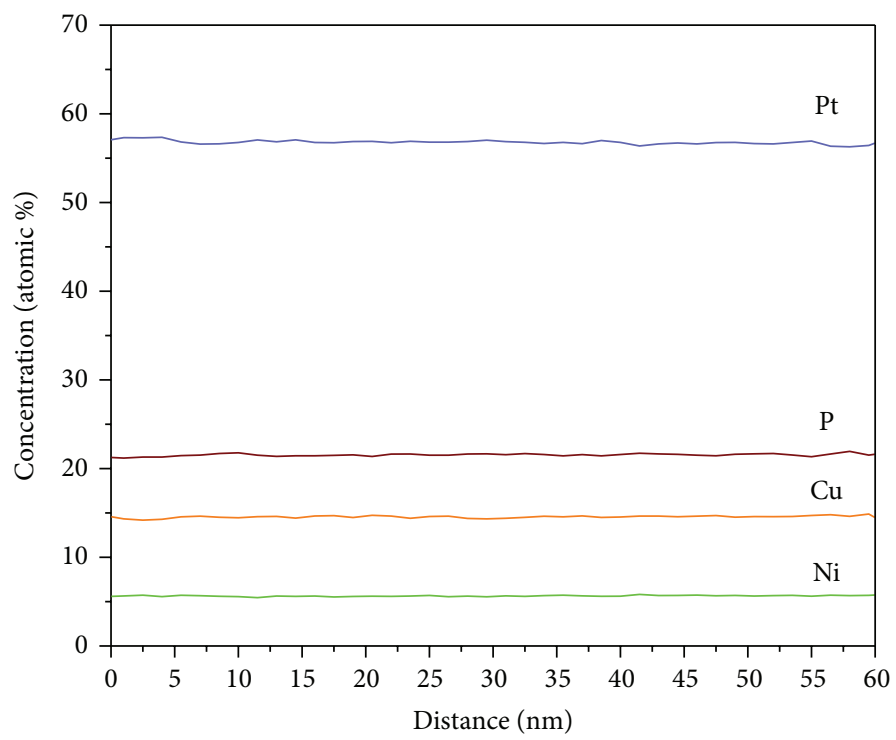

(d)

FIGURE 3: (a) 3DAP reconstruction and (b) elemental distribution for as-cast $\mathrm{Pd}_{43} \mathrm{Cu}_{27} \mathrm{Ni}_{10} \mathrm{P}_{20}$ metallic glass; (c) 3DAP reconstruction and (d) elemental distribution for as-cast $\mathrm{Pt}_{57.5} \mathrm{Cu}_{14.7} \mathrm{Ni}_{5.3} \mathrm{P}_{22.5}$ metallic glass. Atom probe results show homogeneous distribution of all the elements in the as-cast structure of both alloys. 


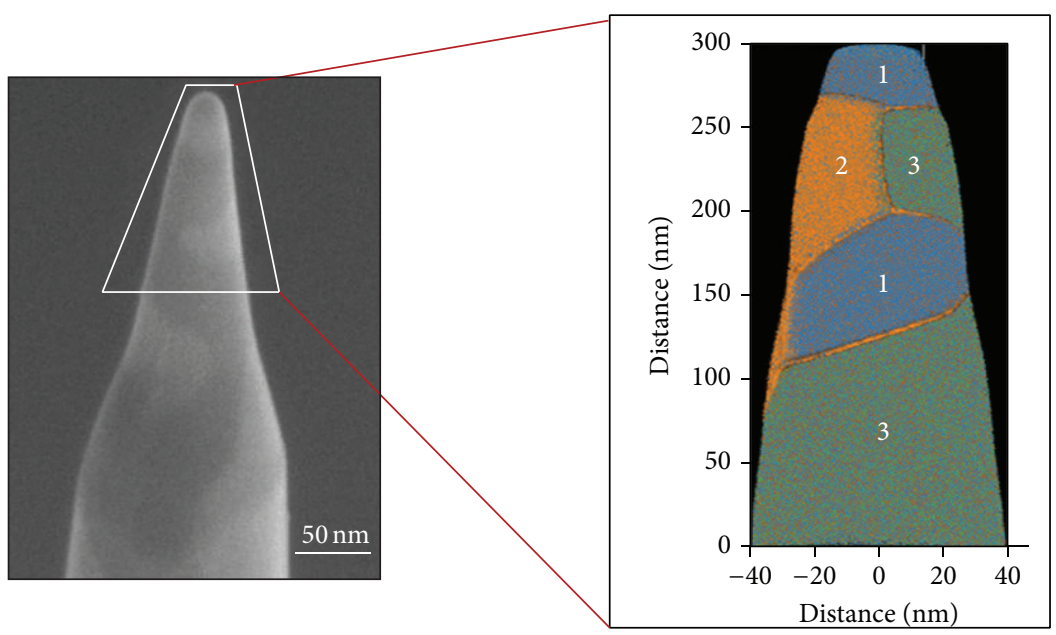

(a)

(b)

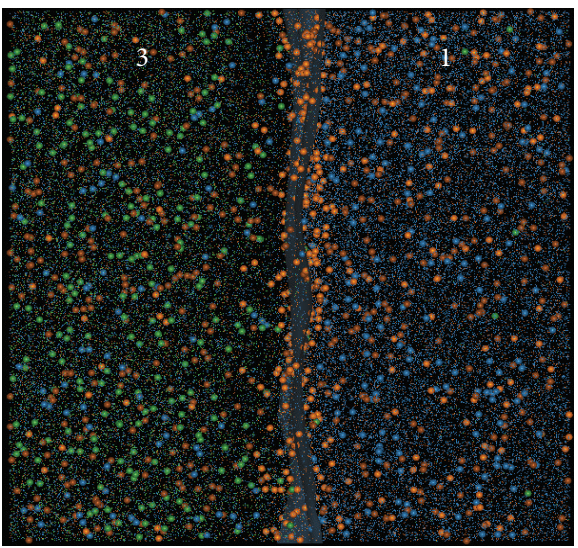

(c)

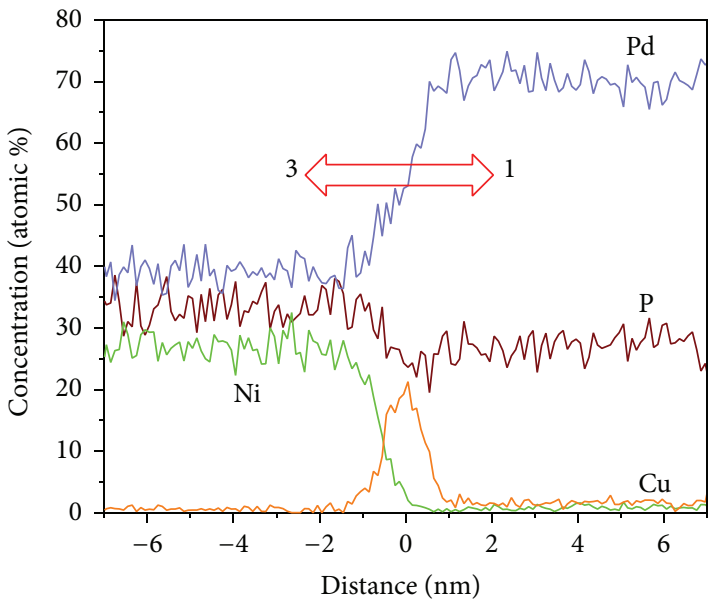

(d)

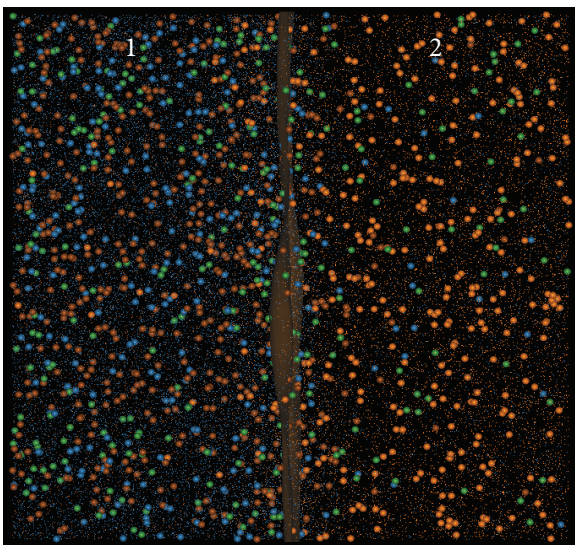

(e)

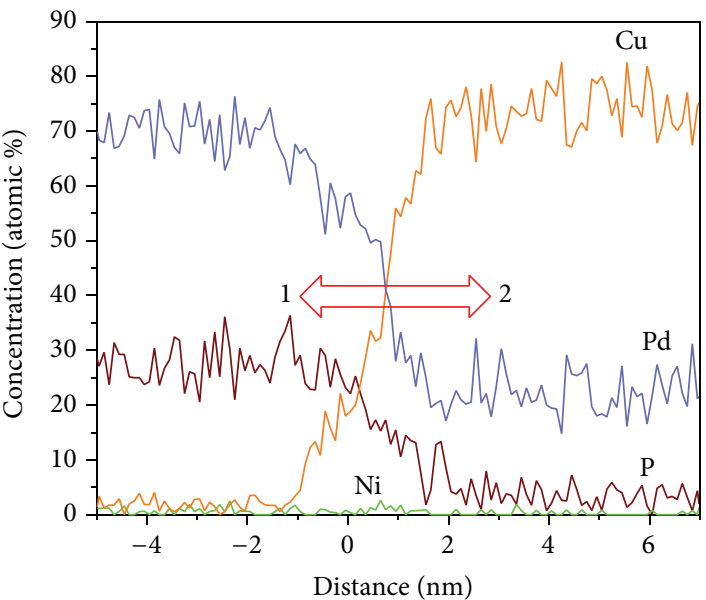

(f)

Figure 4: (a) SEM image of crystallized $\mathrm{Pd}_{43} \mathrm{Cu}_{27} \mathrm{Ni}_{10} \mathrm{P}_{20}$ metallic glass used for atom-probe microscopy; (b) 3DAP reconstruction for $\mathrm{Pd}_{43} \mathrm{Cu}_{27} \mathrm{Ni}_{10} \mathrm{P}_{20}$ metallic glass crystallized by heating it up to $450^{\circ} \mathrm{C}$ with heating rate of $20^{\circ} \mathrm{C} / \mathrm{min}$; (c) elemental map and (d) composition profile across the interface between phases " 1 " and " 3 "; (e) elemental map and (f) composition profile across the interface between phases " 1 " and "2"; phases marked 1,2, and 3 correspond to $\mathrm{Pd}_{7} \mathrm{P}_{2}, \mathrm{PdCu}_{3}$, and $\mathrm{Pd}_{4} \mathrm{Ni}_{3} \mathrm{P}_{3}$, respectively. The thickness of all the interfaces was found to be less than $0.5 \mathrm{~nm}$. 


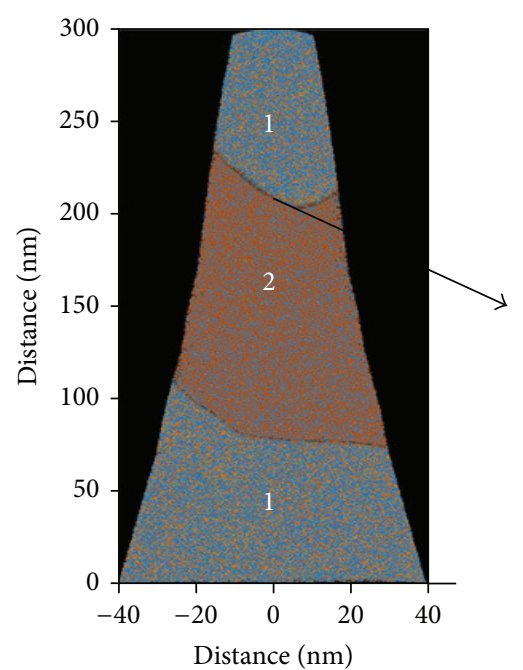

(a)

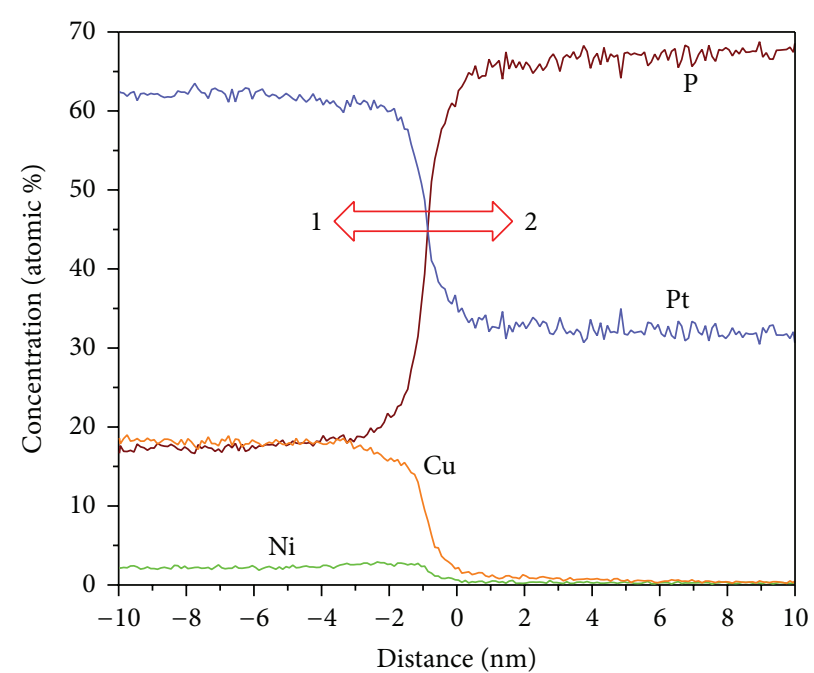

(b)

Figure 5: (a) 3DAP reconstruction for $\mathrm{Pt}_{57.5} \mathrm{Cu}_{14.7} \mathrm{Ni}_{5.3} \mathrm{P}_{22.5}$ metallic glass crystallized by heating it up to $450^{\circ} \mathrm{C}$ with heating rate of $20^{\circ} \mathrm{C} / \mathrm{min}$; (b) elemental distribution and composition profile across the interface between phases " 1 " and "2"; phases marked 1 and 2 correspond to $\mathrm{Pt}_{3} \mathrm{PCu}$ and $\mathrm{PtP}_{2}$, respectively.

TABLE 2: Elemental composition (at. \%) obtained using atom probe microscopy of different phases identified in crystallized $\mathrm{Pt}_{57.5} \mathrm{Cu}_{14.7} \mathrm{Ni}_{5.3} \mathrm{P}_{22.5}$ metallic glass.

\begin{tabular}{lccc}
\hline $\begin{array}{l}\text { Elements } \\
\text { (atomic \%) }\end{array}$ & Phase 1 & Phase 2 & Phase 3 \\
\hline $\mathrm{Pt}$ & 60.2 & 33.5 & 44.5 \\
$\mathrm{Cu}$ & 17.3 & 0.0 & 13.9 \\
$\mathrm{Ni}$ & 2.1 & 0.0 & 19.0 \\
$\mathrm{P}$ & 20.4 & 66.5 & 22.6 \\
Likely phases & $\mathrm{Pt}_{3} \mathrm{CuP}$ & $\mathrm{PtP}_{2}$ & Pt-Cu-Ni-P \\
\hline
\end{tabular}

this study. Many of the zirconium-based metallic glasses show two-stage devitrification: primary nucleation of metastable quasicrystalline phases, followed by transformation of the remaining supercooled liquid to thermodynamically stable phases via secondary crystallization $[13,14]$. These are typically "stronger" liquids (higher value of fragility parameter), which show significant degree of icosahedral ordering in the undercooled liquid $[15,16]$. On the contrary, "fragile" glasses [15] such as $\mathrm{Pd}_{43} \mathrm{Cu}_{27} \mathrm{Ni}_{10} \mathrm{P}_{20}$ and $\mathrm{Pt}_{57.5} \mathrm{Cu}_{14.7} \mathrm{Ni}_{5.3} \mathrm{P}_{22.5}$ show drastic change in liquid properties with change in temperature, particularly close to the glass transition. This favors rapid rearrangement of the smaller metalloid atoms resulting in the formation of multicomponent phosphide phases up on devitrification. Multiple phosphide phases formed for both alloys support the "fragile" liquid behavior.

From the atom probe studies, it is seen that the interface between different crystallized regions is very sharp, with a width of less than 0.5 nanometers. It has been reported previously that a sharp interface (atomically thin) between the different crystallized phases indicate eutectic mode of crystallization, where interface diffusion plays a more dominant role compared to volume diffusion [17]. From the elemental distribution in $\mathrm{Pd}_{43} \mathrm{Cu}_{27} \mathrm{Ni}_{10} \mathrm{P}_{20}$ (Figures 4(c)-4(f)), it is seen that $\mathrm{Cu}$ preferentially segregates at the interface between $\mathrm{Pd}_{4} \mathrm{Ni}_{3} \mathrm{P}_{3}$ (region marked " 3 ") and $\mathrm{Pd}_{7} \mathrm{P}_{3}$ (region marked "1"). Therefore, $\mathrm{Cu}$ not only forms $\mathrm{Cu}_{3} \mathrm{Pd}$ but also segregates to the interface between the non-Cu containing phases. Solid solubility of $\mathrm{Pd}$ and $\mathrm{Ni}$ in $\mathrm{Cu}$ is high, whereas that of $\mathrm{P}$ is low [18]. Therefore, copper segregation (between $\mathrm{Pd}_{4} \mathrm{Ni}_{3} \mathrm{P}_{3}$ and $\mathrm{Pd}_{7} \mathrm{P}_{3}$ ) is likely due to its low solubility with phosphorus and high diffusivity. Copper segregation at the interface has been reported during crystallization of some other metallic glass compositions as well [19].

\section{Conclusion}

Atomic distribution in catalytically active BMGs, $\mathrm{Pd}_{43} \mathrm{Cu}_{27} \mathrm{Ni}_{10} \mathrm{P}_{20}$ and $\mathrm{Pt}_{57.5} \mathrm{Cu}_{14.7} \mathrm{Ni}_{5.3} \mathrm{P}_{22.5}$, was studied using three-dimensional atom-probe microscopy in ascast amorphous and fully crystallized state. The following conclusions may be drawn based on the obtained results:

(1) Both alloys show uniform distribution of constituent elements in the starting amorphous structure, indicating no phase separation.

(2) The Pt alloy showed an acicular eutectic microstructure while the Pd alloy showed a lamellar eutectic structure, which may be attributed to the difference in their critical cooling rates.

(3) A very sharp interface ( $\sim 0.5 \mathrm{~nm}$ as determined from atom probe) was found between the different crystallized phases, which support the eutectic mode of crystallization, where interface diffusion plays a more dominant role compared to volume diffusion. 
(4) The formation of mostly metal-metalloid phosphide phases may be attributed to the "fragile" liquid behavior of both alloys.

\section{Conflict of Interests}

The authors declare that there is no conflict of interests regarding the publication of this paper.

\section{References}

[1] M. Carmo, R. C. Sekol, S. Ding, G. Kumar, J. Schroers, and A. D. Taylor, "Bulk metallic glass nanowire architecture for electrochemical applications," ACS Nano, vol. 5, no. 4, pp. 29792983, 2011.

[2] S. Mukherjee, R. C. Sekol, M. Carmo, E. I. Altman, A. D. Taylor, and J. Schroers, "Tunable hierarchical metallic-glass nanostructures," Advanced Functional Materials, vol. 23, no. 21, pp. 2708-2713, 2013.

[3] R. Jiang, D. T. Tran, J. P. McClure, and D. Chu, "A class of (Pd-Ni$\mathrm{P})$ electrocatalysts for the ethanol oxidation reaction in alkaline media," ACS Catalysis, vol. 4, no. 8, pp. 2577-2586, 2014.

[4] L.-X. Ding, A.-L. Wang, G.-R. Li et al., "Porous Pt-Ni-P composite nanotube arrays: highly electroactive and durable catalysts for methanol electrooxidation," Journal of the American Chemical Society, vol. 134, no. 13, pp. 5730-5733, 2012.

[5] J. Schroers, W. L. Johnson, and R. Busch, "Crystallization kinetics of the bulk-glass-forming $\mathrm{Pd}_{43} \mathrm{Ni}_{10} \mathrm{Cu}_{27} \mathrm{P}_{20}$ melt," Applied Physics Letters, vol. 77, no. 8, pp. 1158-1160, 2000.

[6] J. Schroers and W. L. Johnson, "Highly processable bulk metallic glass-forming alloys in the $\mathrm{Pt}-\mathrm{Co}-\mathrm{Ni}-\mathrm{Cu}-\mathrm{P}$ system," Applied Physics Letters, vol. 84, no. 18, pp. 3666-3668, 2004.

[7] J. Schroers, Y. Wu, R. Busch, and W. L. Johnson, “Transition from nucleation controlled to growth controlled crystallization in $\mathrm{Pd}_{43} \mathrm{Ni}_{10} \mathrm{Cu}_{27} \mathrm{P}_{20}$ melts," Acta Materialia, vol. 49, no. 14, pp. 2773-2781, 2001.

[8] R. Goetzinger, M. Barth, and D. M. Herlach, "Mechanism of formation of the anomalous eutectic structure in rapidly solidified Ni-Si, Co-Sb and Ni-Al-Ti alloys," Acta Materialia, vol. 46, no. 5, pp. 1647-1655, 1998.

[9] C. Ma, N. Nishiyama, and A. Inoue, "Phase equilibria and thermal stability of Pd-Cu-Ni-P alloys," Materials Transactions, vol. 43, no. 5, pp. 1161-1165, 2002.

[10] J.-H. Kim, S.-G. Kim, and A. Inoue, "In situ observation of solidification behavior in undercooled $\mathrm{Pd}-\mathrm{Cu}-\mathrm{Ni}-\mathrm{P}$ alloy by using a confocal scanning laser microscope," Acta Materialia, vol. 49, no. 4, pp. 615-622, 2001.

[11] N. Nishiyama and A. Inoue, "Nucleation and growth behavior of undercooled $\mathrm{Pd}_{42.5} \mathrm{Cu}_{30} \mathrm{Ni}_{7.5} \mathrm{P}_{20}$ melt," Materials Transactions, vol. 43 , no. 5, pp. 1247-1249, 2002.

[12] I.-R. Lu, G. Wilde, G. P. Görler, and R. Willnecker, “Thermodynamic properties of Pd-based glass-forming alloys," Journal of Non-Crystalline Solids, vol. 250-252, pp. 577-581, 1999.

[13] D. H. Kim, W. T. Kim, E. S. Park, N. Mattern, and J. Eckert, "Phase separation in metallic glasses," Progress in Materials Science, vol. 58, no. 8, pp. 1103-1172, 2013.

[14] I. Martin, T. Ohkubo, M. Ohnuma, B. Deconihout, and K. Hono, "Nanocrystallization of $\mathrm{Zr}_{41.2} \mathrm{Ti}_{13.8} \mathrm{Cu}_{12.5} \mathrm{Ni}_{10.0} \mathrm{Be}_{22.5}$ metallic glass," Acta Materialia, vol. 52, no. 15, pp. 4427-4435, 2004.
[15] C. A. Angell, "Formation of glasses from liquids and biopolymers," Science, vol. 267, no. 5206, pp. 1924-1935, 1995.

[16] S. Mukherjee, J. Schroers, Z. Zhou, W. L. Johnson, and W.-K. Rhim, "Viscosity and specific volume of bulk metallic glassforming alloys and their correlation with glass forming ability," Acta Materialia, vol. 52, no. 12, pp. 3689-3695, 2004.

[17] U. Köster and U. Herold, "Crystallization of metallic glasses," in Glassy Metals I: Ionic Structure, Electronic Transport, and Crystallization, H. J. Guntherodt and H. Beck, Eds., vol. 46 of Topics in Applied Physics, pp. 225-259, Springer, Berlin, Germany, 1981.

[18] J. R. Davis, Copper and Copper Alloys, ASM International, Geauga County, Ohio, USA, 2001.

[19] T. Kulik, "Nanocrystallization of metallic glasses," Journal of Non-Crystalline Solids, vol. 287, no. 1-3, pp. 145-161, 2001. 

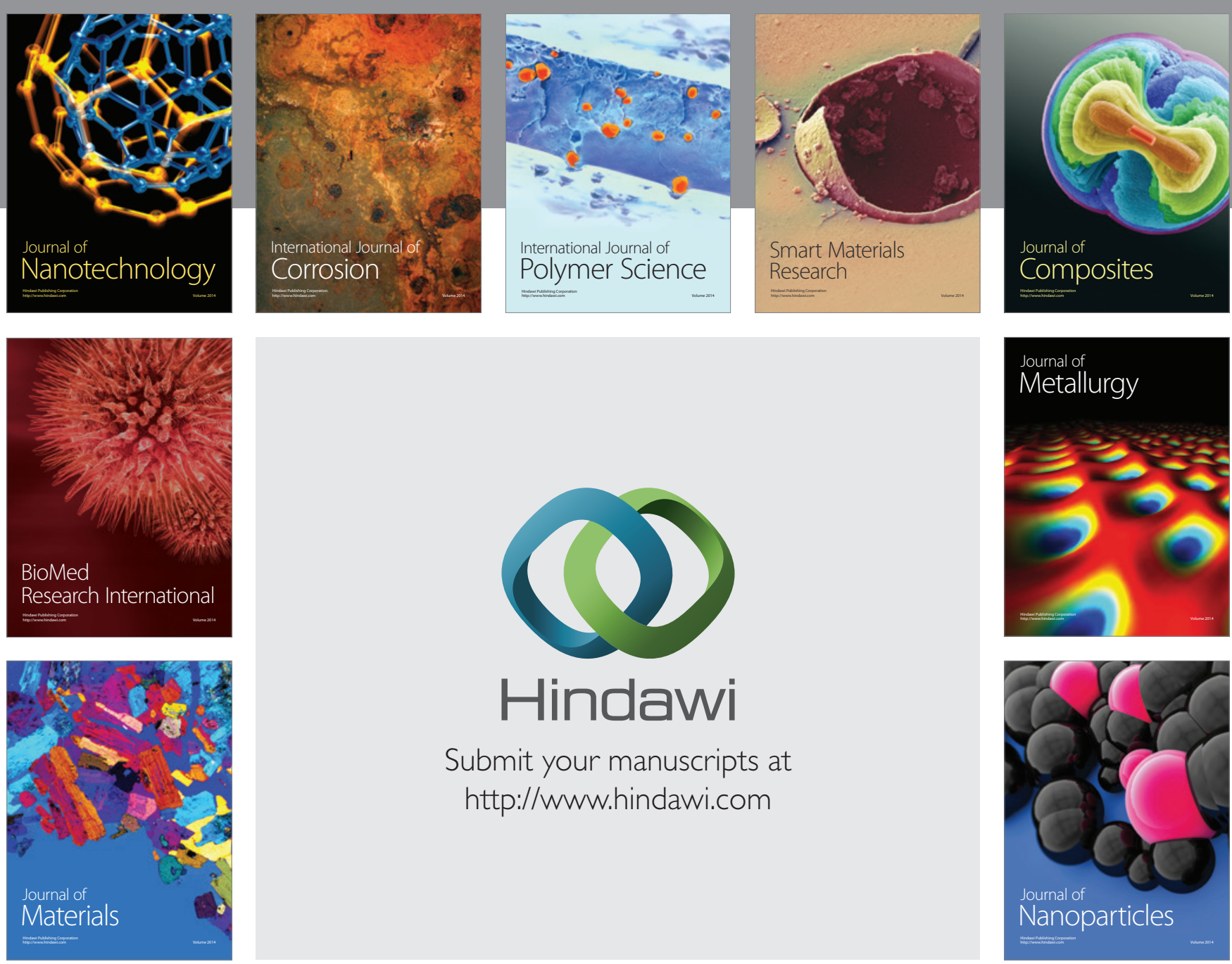

Submit your manuscripts at http://www.hindawi.com
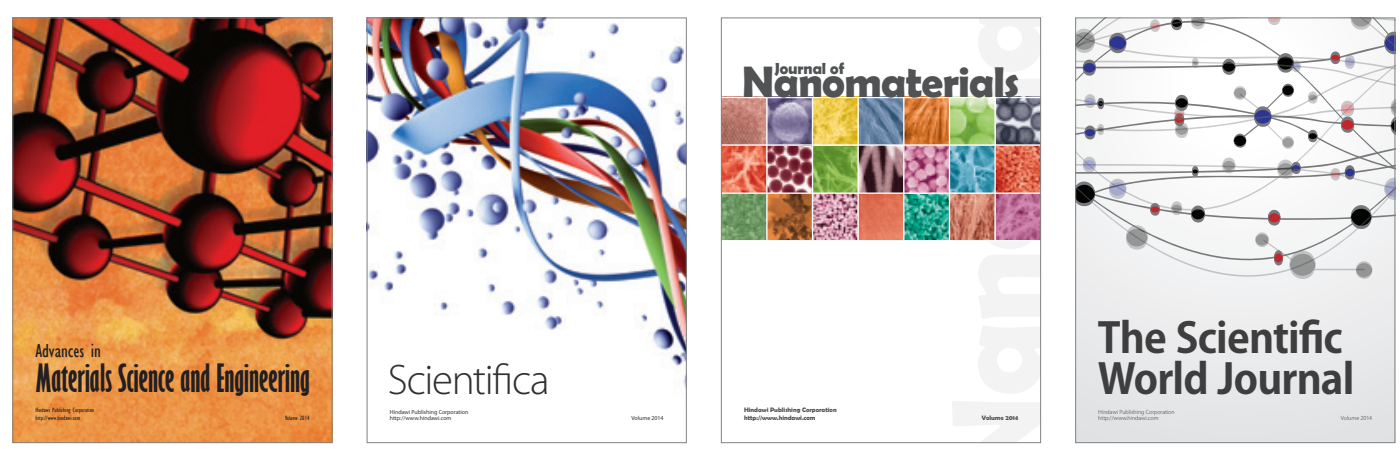

\section{The Scientific World Journal}
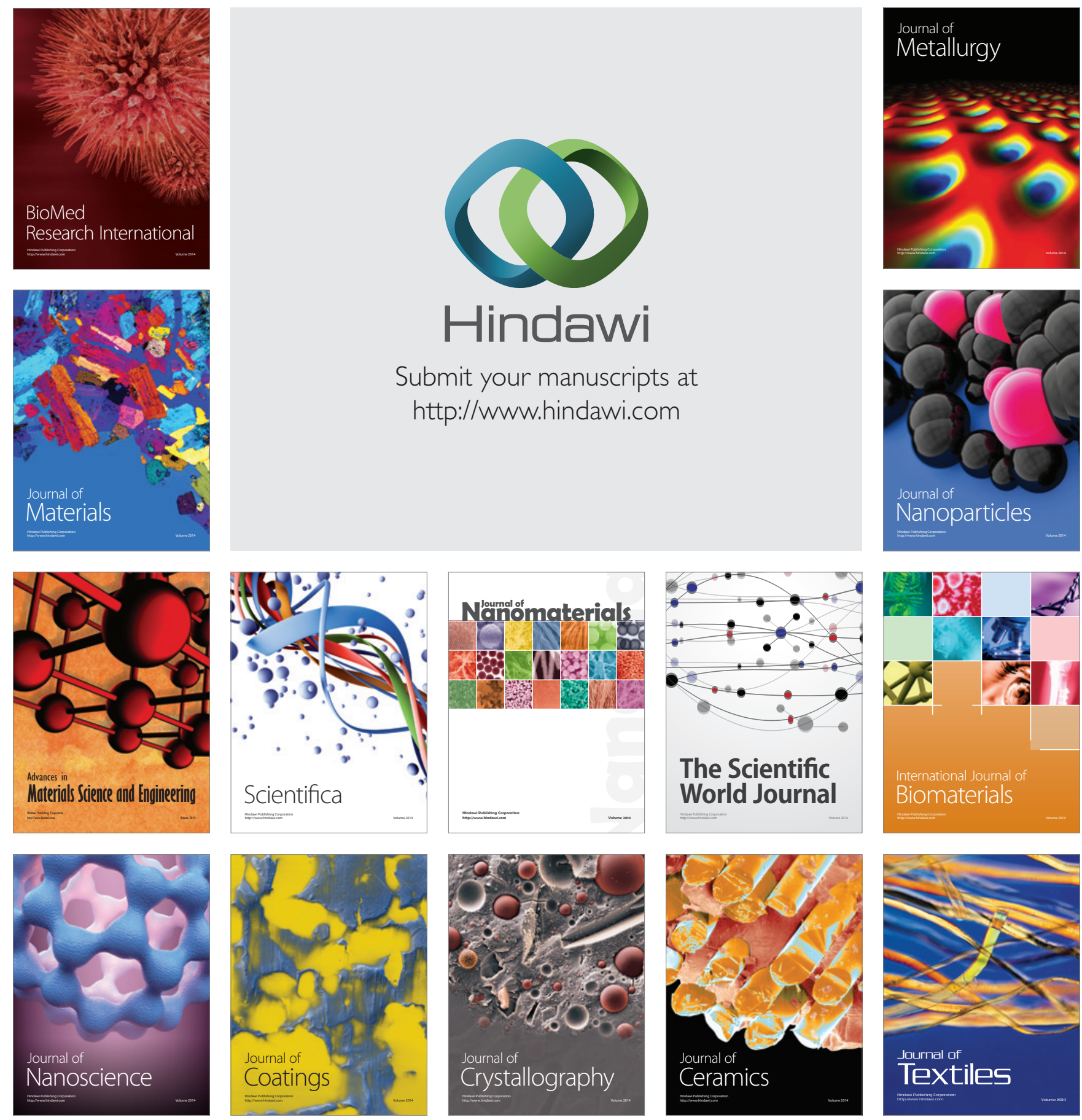